\title{
An Acoustic Turn? Recent Developments and Future Perspectives of Sound Studies
}

\author{
Hans-Joachim Braun \\ Faculty of Humanities and Social Sciences \\ Helmut Schmidt University, Hamburg \\ hjbraun@hsu-hh.de
}

Received 3 March 2014; accepted 12 January 2016.

\begin{abstract}
Since the late 1960s, but particularly since the beginning of the twenty-first century, sound studies have experienced increasing attention in several scholarly disciplines. This development has to be welcomed but, following all the different turns in cultural and social studies, it should not lead us to proclaim a new "acoustic turn." What we do need is a continuing integration of sound studies into the study of the senses as an "area of attention" and, more generally, into the cultural and social studies. Sound studies should be pursued in an interdisciplinary way with a cross-cultural globalized perspective.
\end{abstract}

Keywords: sound studies; music; hearing; perception; acoustics; studies on technology; social studies.

\section{Introduction}

Sound Studies is an interdisciplinary area that studies the material production and consumption of music, sound, noise and silence and how these have changed throughout history and different societies. Among the areas involved are acoustic ecology, sound and soundscape design, anthropology of the senses, history of everyday life, environmental history, cultural geography, urban studies, auditory culture, art studies, musicology, ethnomusicology, literary studies and science and technology studies... Each strand conceptualizes its topic and thus the reality it constructs as its proper subject in highly different ways (Pinch \& Bijsterveld, 2012, p. 7).

Sound studies originated in the late 1960s and have experienced a rapid acceleration during the subsequent decades, particularly from the beginnings of the twenty-first century onwards. In this context, several scholars have wondered whether this development justifies speaking of an "aural," "acoustic," or "sonic" turn. After all, in recent decades we 
have experienced several "turns" in cultural studies including an interpretative, performative, spatial and iconic turn, to mention only a few (Bachmann-Medick, 2010). Is it not the time to do justice to the increased interest in sound matters and proclaim our era as one of an acoustic turn?

Acoustic Turn is the bold title and claim of a book edited by the cultural theorist Petra Maria Meyer in 2008 (Meyer, 2008). Looking at the book's content more closely, we can see, however, that the book does not aim at proclaiming still another turn in cultural studies. It is not as simple as that. Whereas those who propagated the turn in the last decades aimed at re-evaluating and enhancing the state of their own disciplines with obvious academic and political interests in mind, Meyer deals with acoustic phenomena as an integral part of cultural and media studies. The book features phenomenological and psychoanalytical concepts of aurality in relation to music, sound art, film music and acoustic architectural design.

In what follows I will sketch the development of sound studies from the late 1960s onwards, mentioning only a few significant steps in this field. Does this and other research justify the term "acoustic turn," and if so, is it desirable to talk about such a turn? I will also mention several issues in sound studies which, in my view, deserve further investigation.

\section{Origins and Recent Developments}

Until the late 1960 s, the visual element was clearly dominant in scholarly studies relating to the senses, whereas the aural or sonic element was relegated to a second place with the other senses doing even worse. This was to an extent due to some influential books by the Canadian scholar Marshal McLuhan, particularly The Gutenberg Galaxy (1962), in which he argued that the cultural predominance of the visual over the aural was mainly brought about by the invention of the Gutenberg press in 1445. According to McLuhan, this shift from the then dominant aurality to literality and print culture went hand in hand with a shift in the hierarchy of the senses from the primacy of hearing to the primacy of seeing.

Indeed, from the early modern period onwards, new visual technologies such as glasses, telescopes or microscopes have focused on seeing and have extended the possibilities of our visual sense. In science and in scholarship, seeing was generally associated with reason and truth while the other senses, including hearing, were linked with feeling and emotion and held in lower esteem.

However, many key technologies of the nineteenth and twentieth centuries applied in science and medicine were based on the auditory rather than the visual sense. Such was the case of sonic medical technologies like the stethoscope which enabled doctors to examine patients' bodies without performing autopsy. Many other technologies such as the telegraph, gramophone, microphone, telephone and radio, challenged visual habits (Pinch \& Bijsterveld, 2012, p. 14). 
In the late 1960s, the emphasis on seeing and the visual element was called in question by the Canadian composer R. Murray Schafer (Schafer, 1977) as well as Barry Truax (Truax, 1978, 2001) and Hildegard Westerkamp, his collaborators in the "World Soundscape Project." The term and concept of "soundscape" links the outer physical reality with the mental processes which enable us to understand these processes. The Soundscape Project also pursues the objective of mapping past and present soundscapes with the aim to preserve soundmarks and sound environments which are in danger of disappearing. With this project, based at Simon Fraser University in Burnaby, Vancouver, Schafer, Truax and Westerkamp aimed to combine an increased awareness of our sonic environment with a "tuning of the world," contributing to a higher quality sonic environment. The "Lo-Fi-Soundscape" caused by industrialization and mechanization was to be transformed by means of sound design and soundscape composition into a "High-Fi-Soundscape."

In his book Sound and Meaning in the Village Bells (1999) the French historian Alain Corbin investigates the production and use of sound made by village bells in nineteenthcentury France. Village bells had a variety of functions: they were an important means of communication, marked the passing of the hours of the day, summoned villagers to ceremonies, sounded alarms and celebrated joyous occasions. Village bells were symbols and objects of ecclesiastic and civil pride. But bell-ringing not only served purposes of communication: it also reflected the social and religious struggles of the time. Controlling the bells meant controlling the symbolic order and loyalties of French village and country life. Bells were closely linked to the "affect system" which shaped people's lives. In a political move, the rulers of the French Republic tried to take the sacred element away from the bells, limit their religious use and diminish their sensory presence.

The U.S. historian Mark M. Smith argues against the "great divide" à la Marshall McLuhan and others. He deals with sound cultures in North America in the nineteenth century and investigates "sectionalism," the way in which different sound cultures came into existence in the industrial North and the rural South from the beginning of the nineteenth century. In doing so, he focuses on the "sound images" which the Northerners generated from Southern sounds and vice versa. Smith shows that the plantation world of the antebellum South and the industrializing world of the market-driven North sounded different from each other. Southerners were horrified by the noises of the city and praised the bucolic quiet of the plantation. Northerners rejoiced at the "sublime" tones of progress in loud industrial noise but were repelled by the "enfeebling quietude and loud cruelty" of the slave plantation (Smith, 2001, p. 93). Smith deals with sound history as part of political history, but not so much as an added and complementary dimension to a story we already know: his aim, instead, is to open up new "storylines," establish new and different narratives and tell old stories in a new way (Smith, 2001, 2004, 2007).

Jonathan Sterne, too, argues against the "great divide," against the "audio-visual litany," and against the assumption of a more or less fixed and stable relationship between seeing and hearing: hearing as spheric compared to seeing as directed, hearing as encompassing, as opposed to seeing in a perspective, hearing with a bias towards subjectivity compared to 
"objective seeing," or hearing as associated with emotions, as compared to seeing associated with the intellect. Sterne points out convincingly that seeing and hearing are not ahistorical human faculties but historically shaped cultural techniques. They are not constant but subject to change over time. He also argues against those media studies scholars who claim a technical a priori of media. For Sterne, the history of acoustic media does not start with technological inventions such as the telegraph or the telephone, but with the particular historical situation that made such inventions possible. The different ways in which those acoustic media were used were not technologically determined but depended on their cultural interpretations and ways of appropriation. We often treat sound as a natural phenomenon exterior to people, but its very definition is anthropocentric. Without the organ of hearing, there would be no sound in the world, but merely vibrations (Sterne, 2003, p. 11-12). The history of sound implies the history of the body. Sounds are cultural practices and therefore sound studies are an extension of the social and cultural sciences (Sterne, 2003, 2012).

A prominent proponent of sound studies in Germany is Holger Schulze, a cultural theorist from the Berlin University of the Arts. His fields are acoustic ecology and soundscape as well as sound design, and he chairs a research project "Sound Studies Lab" supported by the German Research Foundation. He is also the editor of the high quality series Sound Studies, in which books edited by Spehr on functions of sounds (Spehr, 2009), Schoon and Volmar on sonification (Schoon \& Volmar, 2012), Bijsterveld on soundscape of the urban past (Bijsterveld, 2013) and others were published. In his research Schulze combines the theory of auditory culture, drawing on acoustic ecology and anthropology, with experimental sound design, sonic branding and audio production. He studies sound as both technical-physical emanation and artistic-aesthetical imagination and as a tangible and rich subject of our experience, feelings and thoughts (Schulze, 2008; Pinch \& Bijsterveld, 2012, pp. 7-8). Similar to authors like M. M. Smith, Joy Parr (Parr, 2010) or D. Howes (Howes, 2005), he tries to explore sound phenomena and the auditive realm in the context of and relationship to other sensory experiences (see also Classen, 2014).

For Trevor Pinch \& Karin Bijsterveld, the editors of the Oxford Handbook of Sound Studies (2012), science, technology and medicine are the keys to unlocking the new worlds of sound.

Science, technology and medicine not only create novel sources of sound but also provide us with new tools for using sound and theories about it. What sounds, they ask, have been produced, captured, stored and transferred by science, technology, and medicine? By what means? How have society and culture appropriated these sounds and means; how have scientists, engineers, and physicians listened to the objects, machines and bodies they studied? (Pinch \& Bijsterveld, 2012, p. 6).

The Oxford Handbook of Sound Studies is divided into twenty-three chapters structured around the different sorts of places where sound is experienced. These include the laboratory, the test site, the design studio, and the hospital. In those sites you find experts as test subjects, but also carefully monitored patients and objects. Then there are other sitesthe workshop, the field, the home-which are more open and accessible to non-experts. 
Section I deals with how machine sounds are encountered on the shop floor and at the test site. It includes articles on sound and early American industrialization; industrial noise and noise control in Germany since the 1920s; diagnostic listening to cars; and testing, designing and marketing sounds in the European car industry. Section II "Staging Sound for Science and Art: The Field" deals, inter alia, with making scientific field recordings in ornithology and with the phonograph in laboratory experiments and fieldwork in the period 1900-1920; while Section III focuses on sound and the laboratory, for example the transformation of scientific instruments to musical instruments or the sonification of scientific data. "Sound and the Hospital", containing articles on earplugs, the stethoscope, and cochlear implants, is the topic of Section IV, while Section V on the audio design studio deals with sounds and digital games as well as advertising and electronic music. The two remaining sections concentrate on the consumption of sound and music and on digital storage. Section VI deals among others with the radio dial as a mediating interface, the amateur in the age of mechanical music, and online music sites, while Section VII focuses on hip-hop, technology and the maintenance of racial authenticity, and iPod culture.

The Oxford Handbook of Sound Studies, emphasizing the approach of Science and Technology Studies, is a useful contribution to the literature on sound studies. It features relevant, some rather specialized, contributions to the rapidly growing field of sound studies. In their introduction the editors make it clear that this book does not fully cover the field of sound studies. And indeed: as Daniel Morat states in his review of the book, readers who expect a book presenting the results of a mature research field or even a scientific sub-discipline in the form of a conventional, more or less representative handbook, will not be satisfied (Morat, 2012). In that sense the book is more of a "sampler" of current research in this field extending an invitation to continue research in the fascinating area of sound studies.

The First (International) Conference of the European Sound Studies Association (the "international" is certainly redundant here) on the general theme of "Functional Sounds" took place at the Humboldt University in Berlin, 4-6 October 2013. As Morten Michelsen, the founding chairperson of the European Sound Studies Association, pointed out in his opening address, sound studies can be regarded as a "field" that clearly matters. (Suisman, 2013). By now, several sound studies readers exist and there are also three peer reviewed journals in this field (Journal of Sonic Studies, Interference, and Sound Effects). The thematic starting point of the conference was the observation that functional sounds are core elements in contemporary culture. Its aim was to find out how and to what effect functional sounds are taken up as objects of study by researchers as well as, in design practices, by artists and sound designers. The leading issue was the question whether functional sounds contribute to making our world more "functional," which means more stable, controllable and surveillable, or if critical studies of functional sounds could destabilize and reconfirm practices, discourses and disciplines. The sections were divided into six "streams" dealing with methodologies of sound in the humanities, cultural studies, sonic experience, sonic artistic practices, soundscapes of the urban future, and pop sound. The conference dealt with an impressive number of subjects, ranging from the soundscapes of prisons to jingles played on Lausanne street cars or metal music used in military interrogations, to noise 
cancelling headphones. In June 2014, the second conference of the European Sound Studies Association took take place in Copenhagen on the general theme of "Sound Studies: Mapping the Field."

From 1996 onwards, a number of symposia of ICOHTEC, the International Committee for the History of Technology, have featured sessions on technology, music and sound. Many papers presented there showed that the field of sound studies was developing towards a state of maturity. Papers dealt with museum collections of phonograph recordings, the role of listening in medicine, the measuring of sound and noise in the early twentieth century and the electrification process in the acoustics laboratory. The role of amateurs in sound production and reproduction was a topic, as was the recent decline of the conventional recording studio and the relationship between sound and memory (Braun, 2014, p. 43; Wittje, 2016).

One of the outcomes of those sessions is the volume on Creativity: Technology and Music, edited by Hans-Joachim Braun in collaboration with Susan Schmidt Horning. (Braun 2016). In her article "Creativity in the Trading Zone: Sound Recording as Collaboration," Schmidt Horning focuses on the collaborative aspect. She shows that during the twentieth century creative work in artistic production and in the mass media grew increasingly collaborative. In music, there had been a "division of labour," in that the creative role was with the composer or artist, the technical role with the recorder, and the organizational role with the recording director or producer. But due to technological innovation, that division of labor changed over time and resulted in a greater creative role of recording engineers. They came up with new ways to manipulate sound which, in turn, inspired artists to devise new ways in musical composition. (Schmidt-Horning, 2016). In his contribution on "Technology, Transcultural Idioms, and the Question of Authenticity": Brian Eno and David Byrne in the Studio," Asif Siddiqui deals with Eno's and Byrne's efforts in appropriating non-Western sounds for Western pop music. Those efforts revealed a deep dissonance with regard to the ways in which notions of authorship, community and creativity were bound up in questions of inequality and capital (Siddiqi, 2016).

After a number of exciting developments in sound studies during the last twenty years, some stocktaking is in order. What is the present state of sound studies, how have we reached that state and what are the main issues awaiting further investigation? Papers will deal with methodological issues testing the inter- or transdisciplinary approaches to sound studies, case studies testifying to recent changes within the field, theoretical reflections on its future or historical aspects of sound that may help to understand and to contextualize current developments.

\section{Acoustic Communication and Soundscape Design}

On four days in September 2011, 2012, 2013 and 2014, one-day symposia took place at Green College, University of British Columbia, Vancouver, focusing on "Acoustic Communication and Soundscape Design." The organizers were Barry Truax, Simon Fraser University, Burnaby, Vancouver, and Hans-Joachim Braun, Helmut-Schmidt-University, Hamburg, Germany. Most of the speakers were $\mathrm{PhD}$ and MA candidates in musicology 
from Simon Fraser University and from the University of British Columbia, but there were also papers by established scholars from the School of Communication, Simon Fraser University, and from various schools and departments at the University of British Columbia, including Music, History, Psychology and English. The symposium announcement made it clear that the study of sound can be undertaken through a variety of methods and models. Most of those, however, deal with sound in the abstract; studying sound from the perspective of the listener is to study it as acoustic communication. This approach differs from other approaches in its emphasis on meaning and context. By using the term soundscape to account for the context within which aural meanings occur, the study of acoustic communication encourages us to open our ears to a better understanding of the world we live in. Most of the papers dealt with the following issues:

- $\quad$ role(s) of and changes to acoustic communication in the urban environment;

- modes of listening;

- technology and acoustic ecology;

- musical composition informed by soundscape studies;

- music installation, performing/composing at a given site;

- $\quad$ architecture and urban planning;

- acoustic communication, time, and memory.

Alexander Fisher, a professor of musicology at the University of British Columbia in Vancouver, offered some propositions on soundscapes and acoustic communication from a historical perspective. With Alain Corbin as one of his inspirations, he dealt with the Catholic duchy of Bavaria, which mounted a concerted campaign of religious persuasion, propaganda and coercion to stem the tide of the Protestant Reformation in the period from around 1550 to 1650 . Fisher argued that "confession," which he defines as a constellation of distinctive religious beliefs and practices, was transferred to the human senses through the definition, control, and experience of space. Seen in this light, the mediation of spatial experience through the senses requires an approach that attends to sense perceptions which go beyond the dominant perception of sight. Fisher argued that sound was a particularly powerful medium for the production of sacred space. The Catholic liturgy was embellished with polychoral and instrumental music that overwhelmed the senses and was also timbrally and spatially differentiated. New church architecture and modifications of existing structures led to visually and aurally unified worship spaces enhancing the direct and sensuous perception of the Eucharist ritual. Outside the churches, entire cities became arenas for acoustic communication through bell networks which also made the deployment of military sounds possible. Those sounds were used in processions that defined Catholic space and projected Catholic militancy in a contested religious landscape. But sound was an ambivalent force: It could also be used for disruption and resistance as the persistence of "heretical” Protestant songs showed (see also Fisher, 2014).

Sound, music and space was a topic which Darryl Cressman addressed in his work on the concert hall as a medium of musical culture, describing attentive listening and musical culture in the nineteenth century. Cressman focused on the origin of mid-nineteenth-century concert halls, particularly the Concertgebouw in Amsterdam. He argued convincingly 
that sociotechnical studies of musical culture are often written in a way to suggest that technology precedes and shapes musical culture. This approach is deficient because listening to music is then no longer recognized as a cultural activity in its own right. To remedy this, Cressman used a cultural theory of listening which he applied to explain technical mediation, in this case the designing and building of concert halls. He made clear that in the early nineteenth century European musical culture underwent a significant transformation. The combination of romantic musical aesthetics and bourgeois patronage altered the culture of listening. Over the course of the nineteenth century, attentive listening, as opposed to the generally unfocused music listening of the aristocracy in the eighteenth century, became the norm. This idea of attentive listening was a prerequisite for the design of concert halls in the nineteenth century. They originated in different European cities as monuments to attentive listening and its corresponding musical culture. Concert halls were thus mediums of musical culture shaped by cultural assumptions on how we should listen to music (see also Cressman, 2016).

How is sound connected with the cultural and socio-economic memory of a place? This is one of the questions Vincent Andrisani, School of Communication, Simon Fraser University, tried to answer. In his "The Song of Sweetness: Music, Urban Space, and the Sounds of the Ice Cream Vendor in Havana," he focused on ice cream vendors and the changing way in which they advertised their product acoustically over the last 150 years as well as the reception of this advertising by the population of Havana. In many cities worldwide, the heralding music of ice cream vendors is immediately recognizable and associated with pleasant feelings on the part of the consumers. Andrisani pointed out that, in the case of Havana, these sounds have absorbed added layers of meaning and significance that are particular to this city. About 150 years ago, mobile ice cream vending was announced by the prégon: a signature street cry used by ice cream vendors. During the Republican era from the early twentieth century onwards, however, American advertising practices were adopted, which meant that ice cream came to be associated with the sound of an electronic music box. Although the political regime changed, this practice continued until the collapse of communism in 1991. In the following decade, the sounds of the ice cream vendors were silenced due to the poor living conditions of the population. Afterwards, private enterprise and improved living conditions have led to a resurrection of the ice cream vendor who is now, again, part of the soundscape of Havana.

The case of the Havana ice cream vendor is a good example of sound and its relationship with the changing social, economic, and political conditions. Regarding the local population as (potential) ice cream buyers, the ice cream vendor is culturally significant as a symbol of a social practice and its change over time. The re-emergence of the ice cream vendor sound in the early twenty-first century is symbolic of a novel state of socio-economic conditions. But for the older people there is yet another layer based in memory: a sense of nostalgia for childhood, for sweetness and, at least for some of them, for the American Dream. Andrisani's talk showed an intriguing link between sound, memory and changing living conditions over time. 
What happens when a newcomer with a sensory repertoire of another city acoustically experiences a new city (Vancouver) and establishes relationships with place attachment in a new context? Ozgun Eylul Iscen, Interactive Arts Technology, Simon Fraser University, investigated the newcomer's acoustic experience of the new city in terms of how it shapes the experience of the city and of everyday life. How does a newcomer perceive the sound and soundscapes of the new city, being equipped with the acoustic repertoire of his former domicile and lacking soundscape competence regarding the new place? In her research, Iscen drew upon the triadic communication model by Barry Truax which analyses the listener, the sound and the environment as a system and a process, using soundwalk and sound diary as qualitative methodologies which complement each other. In order to explore the dynamics of those contexts and experiences, she drew on methods from the field of soundscape studies (Sink, 2009), as well as sonic ethnography (Gershon, 2012). Soundscape composition, as complementary to the practices of soundwalk and sound diary, can be useful for accessing and expressing the complex embodied situations and tacit knowledge which are not accessible through other media or through language (Iscen, 2014).

Digital recording is comparatively easy and accessible to many people. Yet the machines available in this market make recording processes very much "in the box"; recordists find it difficult to perceive recording tools as a material part of their environment. They deplore that those machines do not resonate with their own soundscape, but are just devices for capturing sound objects. Pietro Sammarco, School of Communication, Simon Fraser University, researches on how to run a community-access studio with an explicit emphasis on the recording process; he perceives this as a way to listen together through technology. This means developing ways to question the standards that coordinate the inter-operations necessary for making recordings. "What would happen," he asked, "if we were to build a recording studio that uses only equipment that has been thrown into the dump?" Digital technology has increased the illusion suggested by electro acoustics that sound seems to float freely, disregarding our environment. By regaining control of the position through which we exercise our listening abilities, by establishing a material relationship with the recording devices, we could regard signals as having been self-made.

Soundscape recordings have a meaning as performances and affordances. Affordance is a term coined by the American psychologist J. J. Gibson to characterize processes through which objects and environments (material and conceptual) provide opportunities for perception and action (Gibson, 1979, 1986). The notion of affordance was developed in connection with studies of visual perception but has then informed different empirical research projects concerned with other senses and with different ways of understanding human/non-human interaction environments. In "Listening with Technology: Soundscape Recording as Affordance and Performance," Jan Marontate and Dave Murphy, School of Communication, Simon Fraser University, focused on case studies of recordists and users of the World Soundscape Project at Simon Fraser University. Recent interviews provide insights into ways in which the art of soundscape recording and subsequent uses of recordings have provided opportunities for perception, cognition and action. Soundscape recordings are not simple objects that can be read in terms of codes and conventions, but 
provide rich insights for the more general study of how object-based technical practices can be used to create regimes of meaning and to enhance our understanding of aural phenomena in communicative action.

In this age of technology, we are constantly connecting, but, at the same time, we are more alone; our technological devices have enabled us to be with each other, but also elsewhere (Turkle, 2011). But how do we listen? What does our experience of listening tell us about the pioneer experience, the transformation and continuity of resource-based living to environmentalism, and the importance of sound in the cultural history of British Columbia's coastal communities? Jennifer Schine's ethnographic focus is on community-supported research involving residents of Echo Bay, British Columbia's fishing and logging community. Using forms of ethnography, storytelling and expression, she explored historical and contemporary ideas about both the global and local environmental crises through listening to the life-story of Billy Proctor, a renowned elder pioneer of the community. Through soundwalking with him, she was able to "hear" the past in the present and understand the importance of historical, contemporary and environmental listening.

Listening in soundwalking defies definitions of sound or music in phenomenological terms: space is constituted through perception as the body moves through it. The structure of the listening environment is therefore changed, one's perception shifts and the space is constituted differently. In her "Cloist(au)ral:Soundwalking sequester" Andrea Dancer, University of British Columbia, Vancouver, argued that soundwalking can be called an act of "com-position," although, using that term binds acoustic phenomena again to the history of music. What might a soundwalk composition recorded for a multi-channel spatialization or the radio sound like? What are its compositional considerations? - These are some of the questions addressed through analysis of one of her soundwalk compositions, entitled "Cloist(au)ral." When playing and interpreting it, what emerged were moments of sequestered listening, a contemporary cloistral experience, a concentration and meditation that retunes the body and conflates inner and outer realms.

In his "From Observation to Composition: Soundwalking and the Work-Concept" Tyler Kinnear, University of British Columbia, Vancouver, dealt with the transition from soundwalking to soundscape composition, pointing out that, since the origins of soundwalking in the early 1970s in the context of the World Soundscape Project, active listening has broadened in concept and aims. Recent scholarship now considers how soundwalking operates as an experimental art form (Drever, 2009). Not yet explored are, however, the ways in which soundwalks problematize the role of the creator, performer and listener. Who organizes what? How do artists interact with their surroundings? Does the way in which a listener comes into contact with a soundwalk shape his or her perception of experimental sounds as music? In order to come to grips with these issues, Kinnear positions soundwalking close to the work-concept, the idea common in the eighteenth century whereby music is understood in terms of the composition and performance of works. Using three compositions from the late 1970s to the late 1990s as examples, he showed that each work 
maintains active listening and soundmaking as two basic elements of soundwalking. But the composers expand these by using recording techniques such as exploring the acoustic subtleties of a sound source by means of a microphone as well as by performance on "found objects." It is also worth noting the medium in which listeners experience those works. In two cases, the soundwalk was experienced as a recording; in the third case the work was enacted live with headphone mediation. With this approach it is possible to consider soundwalks in the light of a broader concept of composition which uses aurality as a compositional tool (Kinnear, 2017).

"Environment and Voice: Soundscape Composition as Cultural Memory" was the title of Nathan Clarkson's and Jennifer Schine's contribution, both scholars from the School of Communication, Simon Fraser University. They produced two audio tours as part of an aboriginal tourism project with the Squamish Lil' Wat Culture Center in Whistler, British Columbia. They explored the methodology developed in the creation of these two collaborative works, combining soundscape composition and narration. Their main objective was to express the relationship between nations and individuals that share an environment. In line with Jonathan Sterne's observation that sound is an artifact of an action, the projects aims at representing the soundmaking of the environments referred to in the narrative parts of the tour. Their objective was to situate the listener in a series of virtual "soundwalks" of cultural memory. In order to achieve this, they made field recordings on location between Vancouver and Whistler supplemented by material of the Vancouver soundscape project from the 1970s and 1990s. The soundscape composition's focus was on achieving a "true" representation of the acoustic space which results in keen attention to sound sources at every stage of the process. These projects demonstrated one of the practical functions of acoustic communication situating the listener in a heightened sense of acoustic awareness.

Tyler Kinnear explored the transformation of environmental sounds using the example of water as material for electroacoustic composition. With the development of recording technology, composers have been interested in this application of water. Approaches include tape manipulations as in Toru Takemitsu's "Water music" (1963), Barry Truax" "Riverrun" (1986), applying granular synthesis, as well as several more recent compositions. In the course of this process, composers have blurred the line between sonic documentation and soundscape compositions. Using transformational theory and spectro-morphology, Kinnear analyzed Damian Keller's "Soretes de Punta" (1998) in which the composer uses synthesized water sounds in order to highlight some of the possible manipulations and interactions of environmental sounds in compositional space. Applying granular synthesis, the composer models the base identity of his piece after acoustical parameters of a water drop. Sounds derived from the base identity serve as the musical material for most of the piece, but the introduction of various streams transform the timbral profile of sonic events. In its role of "transformative agent," the water stream functions as a thread between the base identity and the other sounds heard in the piece. Kinnear demonstrated the merits of transformational theory and spectro-morphology as tools for analyzing electroacoustic compositions. This is particularly true if one examines the ways environmental sounds are used to reconstitute ideas of musical form and sound behavior (Kinnear, 2015, 2017). 
In his paper "Composing Soundwalks for Clinical Use," the same scholar, Tyler Kinnear, together with Mark Nazemi, dealt with an issue which is of great interest in medicine. They discussed a soundwalk project and the question of how the experience of a virtual soundwalk influences patients with chronic pain. They recorded several environments in different parts of Vancouver as binaural recordings, in order to preserve a sense of realism and added narration when the environment was changed. The final pieces were presented to patients waiting for their appointment at a pain clinic. Some participants were provided with the soundwalk compositions while others were given headphones with no sound. Later the patients were asked to complete a questionnaire asking them about their experience. The outcome was that several of those patients who had listened to the soundwalk compositions tended to feel calmer and, according to the doctor, described their symptoms more accurately. Kinnear's and Nazemi's research is one of the several promising examples of the positive effects of sound and music on human health.

Not only the relationship of soundwalking, sound recording and soundscape composition was of interest in the "Acoustic Communication and Soundscape Design workshop," but also the possible transformation of one medium or art form into another. "Can a soundscape become a painting?" asked Liane Gabora from the University of British Columbia, Okanagan. Endeavors like this are not new. Trying to translate one medium into another, and becoming better acquainted with the essence or form in the process, dates back at least to the late nineteenth century. As to music and paintings, musical terminology was used as titles for paintings and music served as a direct inspiration for painting (Brougher, Strick, Weisman, \& Zilczer, 2005). This process of extracting patterns of information from the domain in which they were originally expressed and transforming them into other domains is called ekphrastic expression. In their research, Liane Gabora and her collaborator Apara Ranjan experimentally investigate whether people can match works of art and pieces of creative writing with pieces of music that inspired them. They also attempt to discern which features of the music are shared by the writing and artworks. This research is a good example of exciting research prospects in the field of sound and other media. (Ranjan 2014; Ranjan, Gabora, \& O'Connor, 2013).

\section{Current Projects and Desiderata}

There are some studies trying to deal with sound in a globalized perspective, but we need more of them (e.g. Taylor, 2007; Mitchell, 2002). How is sound studied and conceived of in Asia, Africa, Latin America or the Caribbean? So far, outside of music, the importance of sound and listening has been largely overlooked in Latin American history. A volume edited by A. Bronfman and A. E. Woods partly remedies this (Bronfman and Woods 2012). It analyses the role of sound in Latin America and in Caribbean societies from the late nineteenth century to the present. The contributors examine the importance of sound in the purveyance of power, gender roles, race, community and religion. They make clear that sound is essential to the formation of citizenship and nationalism. Sonic media, and the radio in particular, have become primary tools of political contestation. This volume 
is a useful starting point for the further exploration of issues such as: how do these studies and approaches unsettle, challenge or reinforce a concept like the soundscape? While ethnomusicologists have produced rich accounts of the sonic environments in Asia, Africa or the Caribbean, they have seldom turned their attention, for example, to the classical orchestras of Europe. Also, many studies of sound as related to technology, medicine or the media, have been located in Europe or North America. A cross-cultural and interdisciplinary investigation would have to address questions of how sonic practices vary across time and space and address the ways technologies change when moving across continents. If the making of noise has a politics, how do economic inequalities affect the way noise is produced, controlled, and heard? How do race or gender amplify, silence or distort the creation of sound?

We also need a reevaluation of the concept of the soundscape. Regarded as "art," music depends on concepts of creativity and privileges the authenticity of experience. Yet as a "commodity," music involves a variety of actors and institutions, linking producers, distributors and consumers within networks of capital, technology and media. A re-evaluation of the soundscape would therefore have to mediate among those paradigms, asking about the autonomy or constraints of the notion of creativity within the modes of producing and consuming music in the twentieth century (Braun, 2002). What about the concepts of creativity in Africa, Asia or the Caribbean, the ways to translate sound into words and the compatibility across cultures and disciplines?

Apart from the above, here are some more issues of sound studies which deserve further investigation:

Training and disciplining the ear and, in a more general perspective: sound and sound standardization, sonar, the standardization of sound measurement units and the relationship between physicists, musicians and instrument makers as well as the role of science in determining esthetic parameters. Myles Jackson's research findings can serve as an excellent starting point. (Jackson, 2006; Kursell, 2008; Hui, 2013).

"Talking sounds": What terms are used to describe and represent auditory phenomena? What about the specialist language in different disciplines, for example in sound engineering? Sound engineering in a historical perspective has recently been explored in two indepth studies (Schmidt-Horning, 2013; Smyrek, 2014).

Hearing and listening in the military, as opposed to civilian applications.

Designing sound: sound animation, sound design inside and outside cars (Bijsterveld et. al., 2014; Bull, 2007), sound and advertising.

Sound and noise in the workshop/factory. The issue of industrial noise and noise control needs investigation in an international comparative perspective which also considers issues of race, class and gender (Bijsterveld, 2008; Braun, 2012).

In conclusion, let us look at the field of sports, "Sound soccer. Acoustic rhythmical intervention in soccer" is a research project in which Alfred Effenberg, a sports scientist from 
the University of Hanover, cooperated with musicologists, composers and an electronics company (www.sportwiss.uni-hannover.de/soundsoccer_sw.html accessed 13 Feb. 2013). The project explores potential effects of musical synchronization on running and passing within a soccer team. Does team cooperation benefit from musical synchronization in terms of "joint action" in the auditory domain? Should soccer players hear music while passing on the ball and should they hear the same music within a team in total synchrony? Wireless transmitted and synchronized music could work as a time base, enhancing the timing precision between players and provoking distinct running cadences. In the project, tempi of musical pieces were selected in line with typical running cadences in soccer of about 110$160 \mathrm{bpm}$ and were changed to provoke tempo changes, variations of rhythms or dribblings. In an experimental setting, players were subject to a persistent rhythmic beat as an external time-reference for their internal action coordination. Randomly selected teams of five experienced players played matches of $3 \times 10$ minutes on a soccer field which was reduced in size. All players were equipped with earphones and portable receivers to listen to a rhythmic stimulus in different tempi. Test conditions changed in alternating order of ten minutes units: With team A, the stimulus was wirelessly supplied in phase synchrony, while with team B the same stimulus was supplied non-synchronously in five different tempi between 119 and $168 \mathrm{bpm}$. Afterwards, the same happened in reverse. The test finished with both teams playing without stimuli. In total, thirty-two matches were played, eighteen of which included male and fourteen female participants. Unsurprisingly, the rhythmic intervention showed significant results: during a ten minute match, male teams scored on average 0.72 goals more under synchronous than under non-synchronous conditions. But there was a big surprise: female teams did not show any significant effect. Why that was so is not year clear and has to wait for further investigation. But the results indicate that rhythmic stimulation could become a powerful tool for rehearsing team-playing skills. Team play in soccer can be understood as synchronization of coupled complex oscillators. The dynamics of each unit is different from that of the others but there is a (probably non-linear, maybe stochastic) functional relationship between them. If this assumption is correct, it should be possible to change the degree of synchronization by adjusting the individual movement frequencies with the help of acoustic stimuli (Braun, 2015, pp. 196-197).

But there are other applications of sound in soccer:

The footbonaut is a robot designed to enhance the soccer player's reaction time and speed of controlling the ball but also improve his or her precision in passing the ball. The soccer robot's throwing the ball into the field is accompanied by a light and sound signal, a bleep. The device was invented by the musician Christian Güttler and has been successfully applied by several high-class teams (Braun, 2015, pp. 198-199).

What are the effects of soccer chants and vociferous fan support on the performance of soccer teams? It will not come as a surprise that they can have the desired effect. However, all those efforts can also be counterproductive. Social psychologists call this "the choking under pressure effect" which can stifle soccer players' performance particularly on those occasions when much is at stake (Braun, 2015, pp. 191-194). 


\section{Conclusion}

Coming back to the title of this article: have we, during the last two decades, experienced an "acoustic" turn in cultural studies and is it, generally speaking, desirable to proclaim such a turn? During the last decades we have or are supposed to have experienced numerous "turns" in cultural studies which have caused states of acute dizziness in many observers, including myself, There were some honorable, reasonable motifs behind some of these turns, but there were also obvious marketing intentions to advance one's field in the competition for intra- and extra- academic resources. Even as a staunch advocate of the worthy cause of sound investigation, I am convinced that we can do without another, this time acoustic, turn in cultural and social studies. What we do need, however, is to advance the many multifaceted endeavors in the field of sound studies: to sharpen and deepen the focus of some of them. Not a new acoustic turn is in order, but continuing high level contributions to the field of sound studies as an extension of the cultural and social sciences. The aural element should be studied in the context of and in relation to the other senses. But the main objective should be the integration of sound studies as an "area of attention" into the cultural and social sciences with special emphasis on historical aspects. They should be pursued in an interdisciplinary way and, particularly, from a cross-cultural, globalized perspective.

\section{References}

Bachmann-Medick, D. (2010). Cultural turns: Neuorientierungen in den Kulturwissenschaften (4 ${ }^{\text {th }}$ ed.). Reinberk, Germany: Rowohlt-Taschenbuch-Verl.

Bijsterveld. K. (2008). Mechanical sounds: Technology, culture, and public problems of noise in the twentieth century. Cambridge, MA: MIT Press.

Bijsterveld, K. (Ed.). (2013). Soundscape of the urban past: Staged sound as mediated cultural heritage. Bielefeld, Germany: Transcript

Bijsterveld, K., Cleophas, E., Krebs, S. \& Mom, G. (2014). Sound and safe: A history of listening behind the wheel. Oxford, UK: Oxford University Press.

Brougher, K., Strick, J., Weisman, A., \& Zilcser, J. K. (2005). Visual music: Synaesthesia in art since 1900. London, UK: Thames \& Hudson.

Braun, H.-J. (Ed.). (2002). Music and technology in the twentieth century. Baltimore, MD: Johns Hopkins University Press

Braun, H.-J. (2012). Turning a deaf ear? Industrial noise and noise control in Germany since the 1920s. In T. Pinch \& K. Bijsterveld (Eds.), The Oxford handbook of sound studies (pp. 58-78). Oxford, UK: Oxford University Press.

Bronfman, A., \& Woods, A. G. (Eds.). (2012). Media, sound \& culture in Latin America and the Caribbean. Pittsburgh, PA: University of Pittsburgh Press.

Bull, M. (2007). Sound moves: iPod culture and urban experience. London, UK: Routledge 
Corbin, A. (1999). Village bells: Sound and meaning in the nineteenth-century french countryside. London, UK: McMillan.

Drever, J. L. (2009). Excerpts on Discovery. BBC World Service.

Gershon, W. (2012). Sonic ethnography as method and in practice: Urban students, sounds and making sense of science. Anthropology News, 53(5), 5.

Gibson, J. J. (1977). The theory of affordance. In R. Shaw \& J. Brandsford (Eds.), Perceiving, acting, and knowing: Toward and ecological psychology (pp. 67-82). Hillsdale, NJ: Lawrence Erlbaum.

Hui, A. (2013). The psychophysical ear: Musical experiments, experimental sounds, $1840-1910$. Cambridge, MA: MIT Press.

Gibson, J. J. (1982). Reasons for realism: Selected essays of James J. Gibson. (E. Reed \& R. Jones, Eds.). Hillsdale, NJ: Lawrence Erlbaum.

Jackson, M. (2006). Harmonious triads: Physicists, musicians, and instrument makers in nineteenth century Germany. Cambridge, MA: MIT Press.

Kursell, J. (Ed.). (2008). Sounds of science - Schall im Labor 1800 - 1930. Berlin, Germany: MaxPlanck-Institut für Wissenschaftsgeschichte.

McLuhan, M. (1962). The Gutenberg galaxy: The making of typographic man. Toronto, ON: Toronto University Press.

Meyer, P. M. (Ed.). (2008). Acoustic turn. Munich, Germany: Fink.

Mitchell, T. (Ed.). (2002). Global noise: Rap and hip hop outside the USA. Hanover ,NH: Wesleyan University Press.

Morat, D. (2012, November 11). Reviews: Sound Studies. H-Soz-u-Kult. Retrieved 2014, January 11 from https://www.hsozkult.de/publicationreview/id/rezbuecher-17385?language=en

Pinch, T., \& Bijsterveld, K. (2004). [Introduction]. In sound studies: New technologies and music. Social Studies of Science, 34(5), 635-648.

Pinch, T., \& Bijsterveld, K. (Eds.). (2012). The Oxford handbook of sound studies. Oxford, UK: Oxford University Press.

Schafer, R. M. (1977). The tuning of the world. New York, NY: Knopf.

Schmidt-Horning, S. (2013). Chasing sound: Technology, culture and the art of studio recording from Edison to the LP. Baltimore, MD: Johns Hopkins University Press.

Schoon, A., \& Volmar, A. (Ed.). (2012). Das geschulte Ohr: Eine Kulturgeschichte der Sonifikation. Bielefeld, Germany: Transcript.

Schulze, H. (2008). Sound Studies: Traditionen - Methoden - Desiderate: Eine Einführung. Bielefeld, Germany: Transcript.

Smith M. M. (2001). Listening to nineteenth century America. Chapel Hill: University of North Carolina Press.

Smith, M. M. (Ed.). (2004). Hearing history: A reader. Athens: University of Georgia Press. 
Smith, M. M. (2007). Sensing the past: Seeing, hearing, smelling, tasting, and touching in history. Berkeley: University of California Press.

Smyrek, V. (2014). Die Geschichte des Tonmischpults: Die technische Entwicklung der Mischpulte und der Wandel der medialen Produktionsverfahren von den 1920er Jahren bis heute. Berlin, Germany: Logos.

Spehr, G., (Ed.). (2009). Funktionale Klänge: Hörbare Daten, klingende Geräte und gestaltete Hörerfahrungen. Bielefeld, Germany: Transcript.

Sterne, J. (2003). The audible past: Cultural origins of sound reproduction. Durham, UK: Duke University Press.

Sterne, J. (Ed.). (2012). The sound studies reader. London, UK: Taylor \& Francis.

Suisman D. (2013). Report from the First International Conference of the European Sound Studies Association. Retrieved 2014, January 22 from http://blog.commarts.wisc.edu/2013/10/18/reportfrom-the-first-international-conference-of-the-european-sound-studies-association/

Taylor, T. (2007). Beyond exotism: Western music and the world. Durham, UK: Duke University Press.

Truax, B. (Ed.). (1978). The world soundscape project's handbook for acoustic ecology. Vancoucer, BC: ARC.

Truax, B. (2001). Acoustic communication (2 $2^{\text {nd }}$ ed.). Norwood, NJ: Ablex.

Turkle, S. (2011). Alone together. New York, NY: Basic Books. 